\title{
EDITORIAL
}

\section{SARCOPENIA: 2020}

\begin{abstract}
J.E. MORLEY
Corresponding author: John E. Morley, MD, BCh, Division of Geriatric Medicine, Saint Louis University, SLUCare Academic Pavilion, Section 2500, 1008 S. Spring Ave., 2nd Floor, St. Louis, MO 63110, USA, Email: john.morley@health.slu.edu, Twitter: @drjohnmorley
\end{abstract}

Key words: Sarcopenia, elderly, muscle strength, grip strength, function.

Over the last 20 years sarcopenia has been recognized as a major geriatric syndrome with its own ICD-10-CM billable code (M62:84) (1) Numerous societies have recognized it should be diagnosed by having a low measurement of muscle strength, e.g., grip strength, as well as a low fat free mass (2-5). Sarcopenia should be screened for using the SARC-F (6). A number of papers have found that SARC-F is highly specific at identifying persons with sarcopenia that have poor outcomes (7-12). When SARC-F is combined with a measurement of calf circumference (SARC-CalF) it has better sensitivity (13, 14). In over 10,000 older persons sarcopenia was present in $42.9 \%$ of persons (15). Only $5.3 \%$ of frail persons were nonsarcopenic. In a younger population utilizing the SARC-F as part of the Rapid Geriatric Assessment mobile APP, 15.1\% were sarcopenic (16). In persons with a positive SARC-F exercise for 12 months returned the SARC-F score to the normal range (17) (Figure 1).

Cawthon et al (18) showed that the D3-Creatine dilution method was better at predicting functional activity and mortality compared to DEXA-measured appendicular lean mass/height. Madden et al (19) showed that point of care of ultrasound is an excellent measure of vastus medialis mass and correlates well with muscle strength.

Osteosarcopenia is defined as a low bone and muscle mass and strength (20). It is associated with an increase in frailty, falls, hospitalizations and mortality. In persons with sarcopenia high-intensity resistance training over a year increased leg press strength and lumbar bone mineral density (21).

2020 was the year that demonstrated the importance of physical therapy for treating sarcopenia (22). The Izquierdo group clearly demonstrated that 2 sessions daily of an exercise program in hospital improves muscle power and functional outcomes $(23,24)$. A meta-analysis confirmed that exercise interventions in acutely older adults in hospital enhanced physical performance and functional independence $(25,26)$. Wang et al (27) showed that a hospital exercise program enhanced gait speed. Exercise therapy in hospital also improves cognition (28). In a meta-analysis of over 2,900 older persons, exercise decreased falls and improved physical and cognitive function (29). For persons with sarcopenia higher intensity

Figure 1

SARC-F and SARC-CalF: 15 papers 2020

\begin{tabular}{|l|l|l|}
\hline Component & Question & Scoring \\
\hline Strength & $\begin{array}{l}\text { How much difficulty do you have } \\
\text { in lifting and carrying 10 pounds? }\end{array}$ & $\begin{array}{l}\text { None = 0 } \\
\text { Some = 1 } \\
\text { A lot or unable = 2 }\end{array}$ \\
\hline Assistance in walking & $\begin{array}{l}\text { How much difficulty do you have } \\
\text { walking across a room? }\end{array}$ & $\begin{array}{l}\text { None =0 } \\
\text { Some = 1 } \\
\text { A lot, use aids, or unable = 2 }\end{array}$ \\
\hline Rise from a chair & $\begin{array}{l}\text { How much difficulty do you have } \\
\text { transferring from a chair or bed? }\end{array}$ & $\begin{array}{l}\text { None =0 } \\
\text { Some = 1 } \\
\text { A lot or unable without help = 2 }\end{array}$ \\
\hline Climb stairs & $\begin{array}{l}\text { How much difficulty do you have } \\
\text { climbing a flight of 10 stairs? }\end{array}$ & $\begin{array}{l}\text { None =0 } \\
\text { Some =1 } \\
\text { A lot or unable = 2 }\end{array}$ \\
\hline Falls & $\begin{array}{l}\text { How many times have you fallen } \\
\text { in the past year? }\end{array}$ & $\begin{array}{l}\text { None = 0 } \\
1-3 \text { falls =1 } \\
\geq 4 \text { falls = 2 }\end{array}$ \\
\hline
\end{tabular}

SARC-CalF improved the sensitivity of SARC-F (47.5\%) while keeping similar specificity (92.0\%)

From: Mo YH, Zhong J, Dong X, et al. Comparison of Three

Screening Methods for Sarcopenia in Community-Dwelling Older Persons. J Am Med Dir Assoc 2020;12:S1525-S1610.(14)

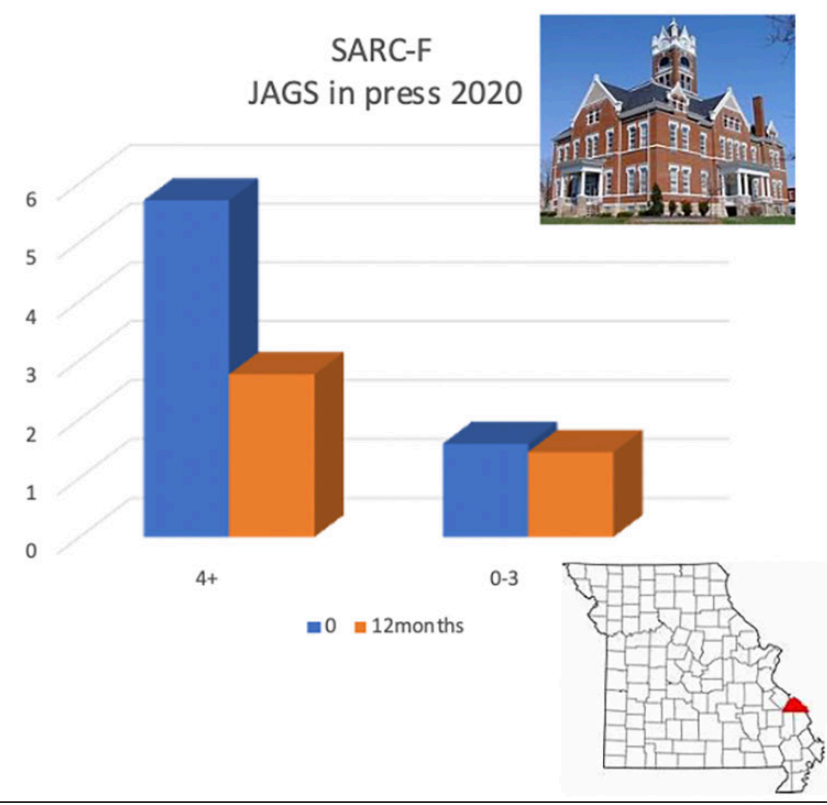

Published online January 8, 2021, http://10.1007/s12603-020-1583-1 


\section{THE JOURNAL OF NUTRITION, HEALTH \& AGING}

resistance exercise is the treatment of choice (30).

Neuromuscular electric stimulation (NES) increased muscle mass and improved the Timed Up and Go test (TUG) (31). NEMS reduced muscle mass loss in critically ill patients (32). A meta-analysis found that vibration therapy in older persons improved strength, five times sit to stand and TUG (33).

It is recognized that high protein intake improves muscle mass in older persons (34). In persons with COPD in the NOURISH study betahydroxy-beta-methylbutyrate improved hand grip strength and reduced death in undernourished older hospital patients (35). Fortetropin, a food derived from egg yolk, increased muscle protein synthesis in older persons (36). Unlike in animals it did not reduce myostatin.

A number of drugs have improved muscle mass and strength compared to placebo but have not been compared to physical exercise (37). Bimagrumab, and activin II receptor inhibitor, failed to improve physical function compared to an adequate diet and exercise (38).

2020 was the year of COVID-19 $(39,40)$. Lockdown lead to increasing sarcopenia $(41,42)$. Exercise (ViviFrail) prevented functional decline in older persons in nursing homes (43). Persons with fatigue with long term Covid-19 were at increased risk for developing sarcopenia (44). The increased cytokines in COVID-19 resulted in severe muscle weakness as part of a cachexia syndrome $(45,46)$.

Of particular interest this year was the work on sestrin-1 (47). Sestrin-1 is low in muscle in old and frail humans. Muscle knockout of sestrins resulted in increased proteolysis in mice. When sestrins were overexpressed, they blocked muscle atrophy in denervated muscles.

During this time SARC-F became more widely accepted as a screening test for sarcopenia. There was further evidence supporting that D3-creatine dilution is the best measure for muscle. Exercise is the treatment of choice for hospitalized, and institutionalized older persons as well as those who undergo lockdown due to the Covid-19 pandemic. Neuromuscular electrical stimulation may be the treatment of choice for persons with intensive care unit-acquired weakness (critical illness myopathy) and post stroke $(48,49)$. There is a need to increase the availability of exercise programs for the prevention and treatment of sarcopenia.

Disclosures: The author declares there are no conflicts.

\section{References}

1. Anker SD, Morley JE, von Haehling S. Welcome to the ICD-10 code for sarcopenia J Cachexia Sarcopenia Muscle 2016;7:512-514.

2. Bauer J, Morley JE, Schols AMWJ, et al. Sarcopenia: A time for action. An SCWD position paper. J Cachexia sarcopenia Muscle 2019;10:956-961

3. Dent E, Morley JE, Cruz-Jentoft AJ, et al. International Clinical Practice guidelines for sarcopenia (ICFSR): Screening, diagnosis and management. J Nutr Health Aging 2018;22:1148-1161

4. Chen LK, Woo J, Arai H. Asian working group for sarcopenia response to the emphasis on anterior thigh muscle mass in sarcopenia diagnosis. J Am Med Dir Assoc 2020;21:1174-1175.

5. Cruz-Jentoft AJ, Baeyens JP, Bauer JM, et al. Sarcopenia: European consensus on definition and diagnosis; report of the European working group on sarcopenia in older people. Age Ageing 2010;39:412-423.
6. Malmstrom TK, Miller DK, Simonsick EM, et al. SARC-F: A symptom score to predict persons with sarcopenia at risk for poor functional outcomes. J Cachexia Sarcopenia Muscle 2016 Mar;7(1):28-36.

7. Woo J, Leung J, Morley JE. Validating the SARC-F: A suitable community screening tool for sarcopenia? J Am Med Dir Assoc 2014;15:630-634.

8. Gomes TUN, Borges TC, Pichard D, Pimentel GD. Correlation between SARC-F score and ultrasound-measured thigh muscle thickness in older hospitalized cancer patients. J Nutr Health Aging 2020;24(10):1128-1130.

9. Ishida Y, Maeda K, Nonogaki T, et al. SARC-F as a screening tool for sarcopenia and possible sarcopenia proposed by AWGS 2019 in hospitalized older adults. J Nutr Health Aging 2020;24:1053-1060.

10. Marini ACB, Perez DRS, Fleuri JA, Pimentel GD. SARC-F is better correlated with muscle function indicators than muscle mass in older hemodialysis patients. J Nutr Health Aging 2020;24:999-1002.

11. Ha YC, Won Won C, Kim M, Chun KJ, Yoo JI. SARC-F as a useful tool for screening sarcopenia in elderly patients with hip fractures. J Nutr Health Aging 2020;24:78-82.

12. Gade J, Beck AM, Ranholt F, et al. Validation of the Danish SARC-F in hospitalized, geriatric medical patients. J Nutr Health Aging 2020;24:1120-1127.

13. Lim JY, Low NA, Merchant RA. Prevalence of sarcopenia in pre-frail community dwelling older adult and utility of SARC-F, SARC-CalF and calf circumference in case finding. J Frailty Sarcopenia Falls 2020 Sep 1;5(3):53-56.

14. Mo Y, Dong X, Wang XH. Screening accuracy of SARC-F combined with calf circumference for sarcopenia in older adults: A diagnostic meta-analysis. J Am Med Dir Assoc 2020;21:288-289.

15. Sanford Am, Morley JE, Berg-Weger , et al. High prevalence of geriatric syndromes in older adults. PLoS One 2020 Jun 5;15(6):e0233857. Doi: 10.1371/journal. pone.0233857. eCollection 2020.

16. Merchant RA, Hui RJY, Kwek SC, et al. Rapid geriatric assessment using mobile app in primary care: Prevalence of geriatric syndromes and review of its feasibility. Front Med (Lausanne) 2020;Jul 8;7:261.

17. Lundy J, Hayden D, Pyland S, et al. An age-friendly health system. J Am Geriatr Soc 2020;Dec 4. Doi:10.111/jgs.16959. [Online ahead of print]

18. Cawthon PM, Blackwell T, Cummings SR, et al. Muscle mass assessed by D3-creatine dilution method and incident self-reported disability and mortality in a prospective observational study of community dwelling older men. J Gerontol A Biol Sci Med sci 2020;May 22.glaa111. doi: 10.1093/Gerona/glaa111. [Epub ahead of print].

19. Madden KM, Feldman B, Anshenkoff S, Meneilly GS. Point-of-care ultrasound measures of muscle and frailty measures. Eur Geriatr Med 2020;Sep 22. Doi:10.1007/ s41999-020-00401-3. [Epub ahead of print].

20. Kirk B, Zanker J, Duque G. Osteosarcopenia: Epidemiology, diagnosis, and treatment -facts and numbers. J Cachexia Sarcopenia Muscle 2020;11:609-618.

21. Kemmler W, Kohl M, Frohlich M, et al. Effects of high-intensity resistance training on osteopenia and sarcopenia parameters in older men with osteosarcopenia-one-year results of the randomized controlled Franconian Osteopenia and Sarcopenia Trial (FrOST). J Bone Miner Res 2020 Sep;35(9):1634-1644.

22. Izquierdo M, Morley JE, Lucia A. Exercise in people over 85. BMJ 2020;5:368:M402. Doi:10.1136/bmj.m402. [Epub ahead of print]

23. Valenzuela PL, Morales JS, Castillo-Garcia A, et al. Effects of exercise interventions on the functional status of acutely hospitalised older adults: A systematic review and meta-analysis. Ageing Res Rev 2020;61:101076.

24. Martinez-Velilla N, Casas-Herrero A, Zambom-Ferraresi F, et al. Effect of exercise intervention on functional decline in very elderly patients during acute hospitalization: A randomized clinical trial. JAMA Intern Med 2019;179:28-36.

25. Saez de Asteasu ML, Martinez-Velilla N, Zambom-Ferraresi F, et al. Changes in muscle power after usual care or early structured exercise intervention in acutely hospitalized older adults. J Cachexia Sarcopenia Muscle 2020;11:997-1006.

26. Saez de Asteasu ML, Martinez-Velilla N, Zambom-Ferraresi, et al. Assessing the impact of physical exercise on cognitive function in older medical patients during acute hospitalization: Secondary analysis of a randomized trial. PLoS Med 2019;16(7)e1002852

27. Wang R, Liang Y, Jiang J, et al. Effectiveness of a short-term mixed exercise program for treating sarcopenia in hospitalized patients aged 80 years and older: A prospective clinical trial. J Nutr Health Aging 2020;24:1087-1093.

28. Papalia GF, Papalia R, Balzani LAD, et al. The effects of physical exercise on balance and prevention of falls in older people: A systematic review and metaanalysis. J Clin Med 2020;9:2595.

29. Saez de Asteasu M, Martinez-Velilla N, Zambom-Ferraresi F, et al. Assessing the impact of physical exercise on cognitive function in older medical patients during acute hospitalization; Secondary analysis of a randomized trial. PLoS Med 2019;Jul 5;16(7):e1002852.

30. Beckwee D, Delaere A, Aelbrecht S, et al. Exercise interventions for the prevention and treatment of sarcopenia. A systematic umbrella review. J Nutr Health \& Aging 2019;23:494-502.

31. Jandova T, Narici MV, Steffl M, et al. Muscle hypertrophy and architectural changes in response to eight-week neuromuscular electrical stimulation training in healthy older people. Life (Basel) 2020;10:184. Doi: 10.3390/life10090184. [Epub ahead of 
print]

32. Segers J, Vanhorebeek I, Langer D, et al. Early neuromuscular electrical stimulation reduces the loss of muscle mass in critically ill patients - A within subject randomized controlled trial. J Crit Care 2020;62:65-71.

33. Dong Y, Wang h, Zhu Y, et al. Effects of whole body vibration exercise on lumbarabdominal muscles activation for patients with chronic low back pain. BMC Sports Sci Med Rehabil 2020;12:78. Doi:10.1186/s13102-020-00226-4 [Epub ahead of print].

34. Bauer J, Biolo G, Cederholm T, et al. Evidence-based recommendations for optimal dietary protein intake in older people: A position paper from the PROT-AGE study group. J Am Med Dir Assoc 2013;14:542-559.

35. Deutz NE, Ziegler TR, Matheson EM, et al. Reduced mortality risk in malnourished hospitalized older adult patients with COPD treated with a specialized oral nutritional supplement: Sub-group analysis of the NOURISH study. Clin Nutr 2020;Sep 4.S0261-4614(20)30447-7. [Epub ahead of print].

36. Evans w, Shankaran M, Nyangau E, et al. Effects of Fortetropin ${ }^{\circledR}$ on the rate of muscle protein synthesis in older men and women: A randomized double-blinded, placebo-controlled study. J Gerontol A Biol Sci Med sci 2020;Jun 29:glaa162. Doi: $10.109 \mathrm{e} /$ Gerona/glaa162. [Epub ahead of print].

37. Morley JE. Pharmacologic options for the treatment of sarcopenia. Calcif Tissue int 2016;98:319-333.

38. Rooks D, Swan T, Goswami B, et al. Bimagrumab vs optimized standard of care for treatment of sarcopenia in community-dwelling older adults: A randomized clinical trial. JAMA Netw Open 2020;3:e2020836.

39. Morley JE, Vellas B. Editorial: COVID-19 and older adults. J Nutr Health Aging 2020;24:364-365

40. Merchant RA, Chen MZ, Ng SE, et al. Letter to the Editor: The role of a geriatrician has become even more important in an academic institution during COVID-19. J Nutr Health Aging 2020;24:681-682.
41. Yamada M, Kimura Y, Ishiyama D, et al. Letter to the Editor: Recovery of physical activity among older Japanese adults since the first wave of the COVID-19 pandemic. J Nutr Health Aging 2020;24:1036-1037.

42. Sepulveda-Loyola W, Rodriguez-Sanchez I, Perez-Rodriguez P, et al. Impact of social isolation due to COVID-19 on health in older people: Mental and physical effects and recommendations. J Nutr Health Aging 2020;24:938-947.

43. Courel-Ibanez J, Pallares JG, Garcia-Conesa S, et al. Supervised exercise (Vivifrail) protects institutionalized older adults against severe functional decline after 14 weeks of COVID confinement. J Am Med Dir Assoc 2020;Dec 6:S1525-8610(20)30970-1. Doi:10.1016/j.jamda.2020.11.007 [Epub ahead of print].

44. Morley JE. Editorial: COVID-19 - the long road to recovery. J Nutr Health Aging 2020-24:917-919.

45. Morley JE, Kalantar-Zadeh K, Anker SD. COVID-19; A major cause of cachexia and sarcopenia? J Cachexia Sarcopenia Muscle 2020;11:863-865.

46. Nestola T, Orlandini L, Beard JR, Cesari M. COVID-19 and intrinsic capacity. J Nutr Health Aging 2020;24:692-695.

47. Jeevendra Martyn JA, Kaneki M. Muscle atrophy and the sestrins. N Engl J Med 2020;24:383:1279-1282.

48. Lad H, Saumur TM, Herridge MS, et al. Intensive care unit - acquired weakness: Not just another muscle atrophying condition. Int J Mol Sci 2020;21:7840. Doi:10.3390/ ijms21217840.

49. Bilek F, Deniz G, Ercan Z, et al. The effect of additional neuromuscular electrical stimulation applied to erector spinae muscles on functional capacity, balance and mobility in post-stroke patients. NeuroRehabilitation 2020;47:181-189. 